\title{
Safe Injection in the Context of IPC: Changing Landscape in Nigeria
}

\author{
Abimbola O Sowande ${ }^{1}$, Olufunke Jibowu ${ }^{2}$, Kelechi Enweruzo Amaefule ${ }^{2}$, Jennifer Pearson ${ }^{3}$, Isa lyortim ${ }^{4}$ \\ 1. Country Director, AIDSTAR-One, Nigeria \\ 2. AIDSTAR-One Nigeria \\ 3. AIDSTAR-One, JSI (HQ) \\ 4. USAID Nigeria \\ doi: 10.3396/IJIC.v10i1.005.14
}

\begin{abstract}
Injection safety and healthcare waste management are cost effective interventions with World Health Organization (WHO) guidelines for health facility assessment and intervention using the three pronged approach at all levels of service delivery. ${ }^{1}$ Interventions by AIDSTAR-One in Nigeria were preceded by a baseline assessment and a follow up with comparative analysis of the key indicators was conducted to document impact of the intervention at focal intervention areas. Post-intervention, needle stick injury reduction was remarkable and statistically significant. Immediate disposal of used sharps improved as well as availability of relevant policies at service sites, differences were also statistically significant. The number of facilities with at least one sharp container present at all procedural points in health facilities also improved. Nigeria has shown a high burden of injections (4.9 per person year in 2004) and promotion of oral medication is on-going. ${ }^{2}$
\end{abstract}

Keywords: Medical Waste Disposal, Needlestick Injuries and prevention and control, Infection Control

\section{Background}

Unsafe injection leads to increased disease burden and deaths from transmission of infection. Cost effective injection safety (IS) interventions encourage best practices especially in low resource countries where the burden is highest. Infection prevention and control (IPC) among health workers, waste handlers, and communities has been documented to decrease the burden over time.

\section{Intervention}

AIDS Support and Technical Assistance Resources, Sector I, Task Order 1 (AIDSTAR-One), funded by the US President's Emergency Plan for AIDS Relief (PEPFAR) through the United States Agency for International Development (USAID), adopted the WHO technical approach that promotes sustainability by working through government structures and stakeholders for policy development

\section{Corresponding author}

Abimbola O Sowande

Country Director, AIDSTAR-One Olufunke Jibowu, Nigeria

Email: bimbo1851@gmail.com 
and implementation. AIDSTAR-One, previously the Making Medical Injections Safer (MMIS) project, conducted national health facility assessment (HFA) in 2004 utilizing the WHO Safe Injection Global Network (SIGN) Revised Injection Safety Assessment Tool (Tool C). ${ }^{3}$ Targeted health facilities received technical assistance including training and capacity building; provision of seed stock of injection safety (IS) commodities, behavioural communication and changes to effect new skills, training and seed stock for appropriate health care waste management (HCWM), and supportive monitoring and evaluation to guide interventions for effective impact. Investors were encouraged to manufacture IS commodities in country to support the intervention. Community interventions, through existing credible structures, aimed to reduce unnecessary injections, and HCWM interventions focused on a minimum package of best practice standards at the health facility level and through community involvement.

The Project set specific objectives to reduce unnecessary injections and at the same time improve the safety of essential injections and ensure safe management of sharps waste. To combat stock outs, the project set the objective to ensure continuous availability of injection safety commodities at service delivery points. Training of health workers and advocating for behaviour change to improve injection safety and HCWM was a key strategy. To achieve these objectives, AIDSTAR-One also supported the Ministry of Health to develop injection safety and HCWM policies and form a national injection safety forum to monitor and give guidance to IS and HCWM activities. The introduction of the use of re-use prevention syringes and safety boxes into curative services through training and provision of seed stock was also accomplished.

To address the high demand for injections, several communities in the intervention states were sensitized on injection safety messages. To strengthen the policy environment, the project facilitated the development of the National Injection Safety Policy in 2007, the National IPC Policy and Strategy in 2013 and the National Healthcare Waste Management Policy, also in 2013.

\section{Results}

The health facility assessment revealed a high burden of injection with 4.9 injections per person per year alongside a high demand for injection while stock outs of needles/syringes were common. Common dangerous practices by health workers observed included two-handed recapping. Almost half of the health workers interviewed reported needle stick injury in the previous six months. ${ }^{4}$

There was also a universal lack of facilities for the disposal of health care waste. The project identified major challenges including a lack of a national policy on injection safety and HCWM, frequent stock outs of injection supplies, and frequent needle stick injuries due to unsafe practices. In addition, safety boxes were only being used for immunisation, and not in the curative sector, and there were no manufacturers of safety boxes in Nigeria.

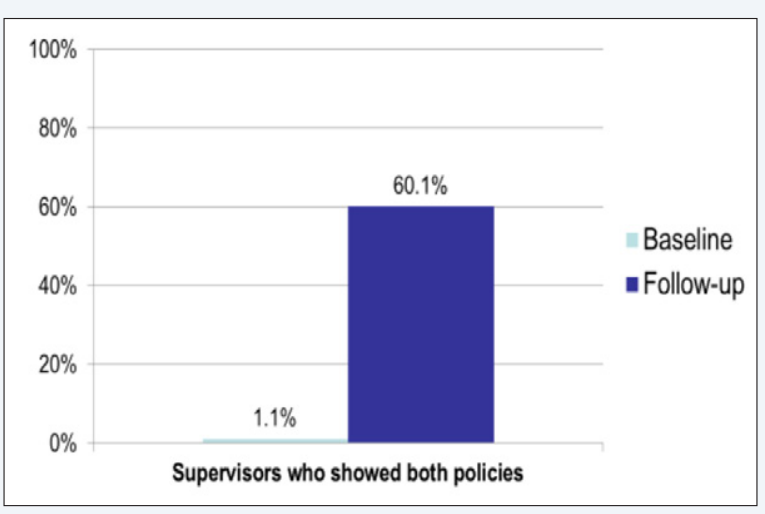

Figure 1. Supervisors who showed both IS and HCWM policies

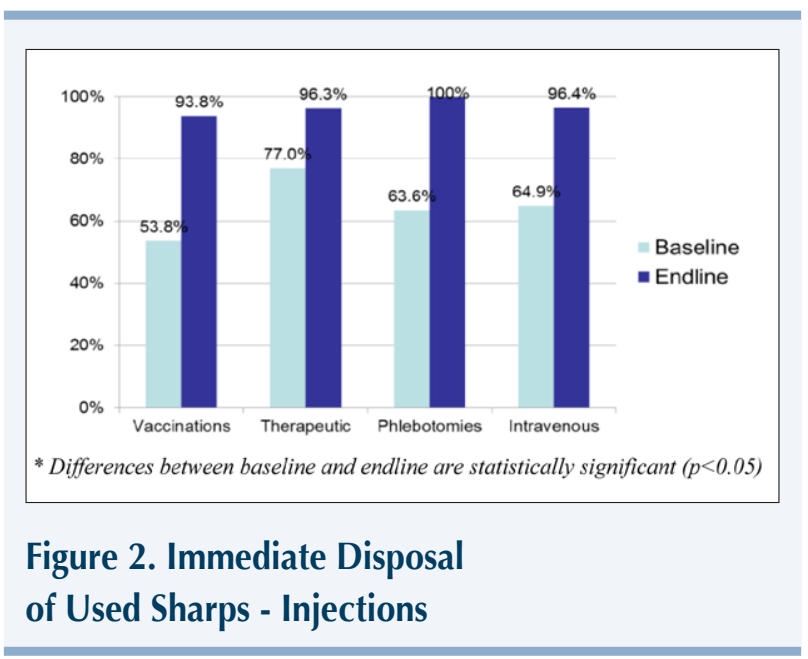




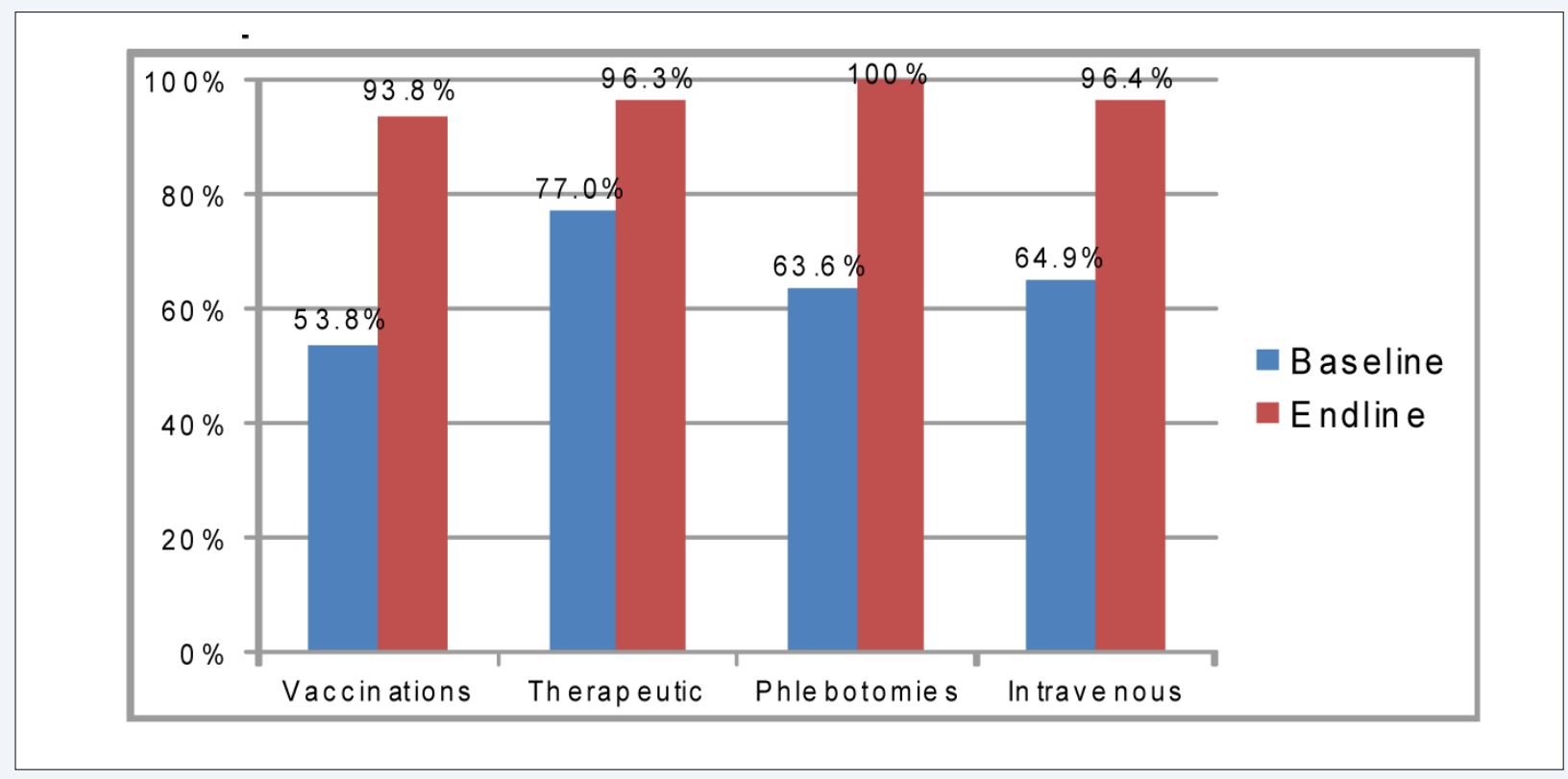

Figure 3. Facilities with at least one sharps container present in all procedure areas

A comparative health facility assessment carried out by AIDSTAR-One (2011-2012) showed statistically significant improvements in availability of IS/HCWM policies at the facility level (Figure 1), immediate disposal of used sharps (Figure 2), and facilities with at least one puncture resistant/leak proof sharps container present in all areas where procedures are performed (Figure 3$)^{5}$

In addition, several local Nigerian manufacturers have been identified that produce personal protective equipment (PPE) and health care waste management segregation commodities. Two factories have initiated production of re-use prevention syringes and one produces safety boxes.

\section{Challenges}

The Nigerian health system is generally weak, attrition of trained personnel due to brain drain is a continuing challenge, and health worker behavioural change is gradual. Another challenge was working with the 3 -tiered government with each tier autonomous and independent of each other.

Staff attrition was another challenge with frequent transfers of already trained staff. The competing needs of the Ministry of Health were another challenge, injection safety and health care waste management may not always receive the necessary attention and budget. The lack of environmentally safe final disposal technologies in many areas of the country was also a challenge as the project was unable to undertake capital intensive options like the procurement of high temperature incinerators.

A key lesson learned from the activities was that advocacy at all levels and at every opportunity yields results. Working with existing structures on the ground is essential. Continuous supportive supervision was found to be effective in improving the quality of services.

\section{Conclusion}

Injection safety and health care waste management interventions in countries with low resources, such as Nigeria, can make steady progress over time as stakeholders appreciate their importance as key IPC measures to ensure the safety of the health workforce, patients, and communities.

\section{References}

1. Kane A, Lloyd J, Zaffran M, Simonsen L, Kane M. Transmission of Hepatitis B, Hepatitis C and Human Immunodeficiency Viruses through unsafe injections in the developing world: model based regional estimates. Bulletin of the World Health Organization 1999; 77(10): 801-807.

2. Government of Nigeria. Injection Safety Assessment in Nigeria. 2004. http://nigeria.usembassy.gov/uploads/images/ McLyWtfPi8-VIVCnFmfaLQ/Injection_Safety_Assessment_in_ Nigeria.pdf [Accessed March 2013] 
3. World Health Organization Injection Safety. http://who.int/ injection_safety/en/ [Accessed November 2013]

4. Akpan T, Shanadi DB, Collins E, Noel M, Sowande AO. Evaluation of Injection Safety and Health Care Waste Management in Nigeria: 2009 Final Report, March edition. MMIS for the Office of the Global AIDS Coordinator (OGAC) and USAID. http://pdf.usaid.gov/pdf_docs/PNADR651.pdf [accessed March 2013]

5. Akpan T, Jibowu O, Sowande AO, Subramanian S, Magalona $\mathrm{S}$, Pearson J. Assessment of injection safety in selected local government areas in five states in Nigeria: 2012 Followup report. USAID's AIDS Support and Technical Assistance Resources, AIDSTAR-One, Task Order 1. 2012. http://www. aidstar-one.com/focus_areas/prevention/resources/reports/ injection_safety_assessment_nigeria_followup [Accessed November 2013] 